\title{
Synthesis of $\mathrm{ZrO}_{2}$ Nanorods and Their Application as Membrane Materials
}

\author{
Guk-hyun Kwon*, Tae Woo Kim*, Hae In Lee**, Won Chul Cho**, and Heeyeon Kim (1)*; \\ *Energy Materials Laboratory, Korea Institute of Energy Research, Daejeon 34129, Korea \\ **Hydrogen Laboratory, Korea Institute of Energy Research, Daejeon 34129, Korea
}

(Received September 10, 2019; Revised October 1, October 10, 2019; Accepted October 11, 2019)

\begin{abstract}
Zirconia $\left(\mathrm{ZrO}_{2}\right)$ materials are widely used in a variety of energy systems and devices. When nanorod-shaped $\mathrm{ZrO}_{2}$ is used as energy materials, ionic conductivity and mechanical strength can be improved compared to the characteristics of conventional spherical-shaped nanomaterials. In this study, we synthesized $\mathrm{ZrO}_{2}$ nanorods and investigated the shape change of them depending on various synthesis conditions such as precursor concentration, synthesis temperature, synthesis period, and aging period. The obtained nanorods were casted into a membrane for alkaline water electrolysis system and subjected to basic performance evaluation for use as a separator. The structure and the shape of the nanorods were characterized by X-ray diffraction (XRD), scanning electron microscopy (SEM), and the like.
\end{abstract}

Key words : $\mathrm{ZrO}_{2}$ nanorod, Membrane, Hydrothermal synthesis, Alkaline water electrolysis system

\section{Introduction}

$Z$ $\mathrm{rO}_{2}$ material is widely used in superplastic structural ceramics, transformation toughening, electrochemical devices, catalysis, and sensors due to its perfect crystallinity, large specific surface area, and small dimension. ${ }^{1-6)}$ The moisture sensitivity is significantly increased when the material is synthesized into nanorods up to $8 \mathrm{~nm}$ in diameter and $22 \mathrm{~nm}$ in length. Among the literatures on the synthesis and applications of $\mathrm{ZrO}_{2}$ materials, few studies have examined nanorod-shaped $\mathrm{ZrO}_{2}$. In particular, the use of $\mathrm{ZrO}_{2}$ nanorods in electrodes and membranes can improve the ionic conductivity and the mechanical strength. ${ }^{7,8)}$ To date, $\mathrm{ZrO}_{2}$ nanorods have been synthesized by annealing of a $\mathrm{Zr}$ precursor powder, ${ }^{9)}$ concentration-dependent solution deposition, ${ }^{10)}$ or chemical vapor deposition. ${ }^{11)}$ These methods of synthesizing $\mathrm{ZrO}_{2}$ nanowires involve multi-step processes, most of which require high energy. This study employed hydrothermal synthesis to fabricate $\mathrm{ZrO}_{2}$ nanorods at low temperature levels. This method is more convenient and useful for mass production since the nanorods can be synthesized simply by optimizing conditions such as precursor concentration, synthesis temperature, and synthesis time. ${ }^{12,13)}$ The synthesized nanorods were used as a material for the membrane of an alkaline water electrolysis system, and basic performances were tested. Alkaline water electrolysis technology is classified as a low-temperature technique, which uses electricity to split water molecules into hydrogen

Corresponding author : Heeyeon Kim

E-mail : heeyeon@kier.re.kr

Tel : +82-42-860-3613

ORCID

https://orcid.org/0000-0003-3102-4737 and oxygen, ${ }^{14-16)}$ and has been developed to the level of commercialization.

Since membranes for alkaline water electrolysis are used in a strongly basic electrolyte $(30 \% \mathrm{KOH})$, it is important to secure the chemical and mechanical stability of a membrane. Asbestos is a conventional and commercialized membrane material with a reasonable price and a porous structure. However, it shows poor durability in long-term reactions. For instance, they may experience a collapse in structure at higher temperatures than $100^{\circ} \mathrm{C}$ and in $\mathrm{KOH}$ concentration higher than $30 \% .^{5,7,17)}$ Alternative materials to asbestos that have been proposed are porous ceramics such as potassium titanate, $\mathrm{ZrO}_{2}, \mathrm{MgO}$, and $\mathrm{TiO}_{2},{ }^{2)}$ which are easily soaked in an electrolyte due to their hydrophilic nature and do not easily collapse due to their outstanding mechanical strength. However, they have the disadvantage of being less flexible against high mechanical strength. Another alternative material is the polymer membrane, which is flexible and has the advantage of being produced with thin thickness. Such membranes, however, are less durable at high temperatures or under strong alkaline conditions due to their weak mechanical strength. ${ }^{18)}$ As such, researchers are focusing on developing composite materials that combine only the advantages of porous ceramics and polymer materials. To date, the most well-known membrane is Zirfon ${ }^{\circledR}$ manufactured by Agfa corporation. Zirfon ${ }^{\circledR}$ is a reinforced composite membrane that casts slurry mixed evenly with polysulfone (PS) polymer on top of polyphenylene sulfate (PPS) support. It remains durable under strong alkaline conditions, and hardly experiences any collapse in structure. ${ }^{19-21)}$

The purpose of this study is to replace the spherical nanoparticles used in the present Zirfon ${ }^{\circledR}$ membranes into 
the nanorodes, increasing the mechanical strength, flexibility, and reducing ion resistance. ${ }^{7,8,10,11)}$ This study is meaningful to develop our own technology for manufacturing membranes for alkaline water electrolysis system. The structure and properties of $\mathrm{ZrO}_{2}$ nanorods were analyzed using scanning electron microscopy (SEM) and X-ray diffraction (XRD), and the performance of the membrane was evaluated in an alkaline water electrolysis system.

\section{Experimental Procedure}

\subsection{Material}

For the synthesis of $\mathrm{ZrO}_{2}$ nano rods, zirconium(IV) oxynitrate hydrate (Sigma Aldrich, 99\%) was dissolved in distilled water at a concentration of $0.05 \sim 0.5 \mathrm{~mol}$, and mixed with sodium hydroxide ( $\mathrm{NaOH}$, Samchun chemical 98\%). For the fabrication of the membrane, $\mathrm{ZrO}_{2}$ nanorods obtained from hydrothermal synthesis were mixed with $\mathrm{ZrO}_{2}$ nanoparticles ( $-40 \mathrm{~nm}$, US Research Nanomaterials, Inc.) in different proportions, and supported on a polyphenylene sulfide mesh (PPS, thickness of $203 \mu \mathrm{m}, \mathrm{PVF}$ mesh \& screen technology). Polysuflone (PSU) (molecular weight of 35,000, Sigma-Aldrich, 99\%) was dissolved in nmethy-2-pyrrolidon (NMP, Sigma Aldrich $\geq 99 \%$ ) for the binding of the nanoparticles.

\subsection{Synthesis of Zirconia Nanorods}

The concentration of zirconium precursor (Zirconium oxyhydrate nitrate) aqueous solution was varied in the range of 0.01-0.05 mol, and that of the $\mathrm{NaOH}$ aqueous solution in the range of 10-20 mol. The zirconium oxyhydrate nitrate solution was mixed with the $\mathrm{NaOH}$ solution in a beaker, and ethanol was added to facilitate mixing of the solutions. The reactions proceeded for 8 to $72 \mathrm{~h}$ using sol-gel method. The mixing ratio was $30 \mathrm{ml}$ of zirconium solution, $3 \mathrm{ml}$ of $\mathrm{NaOH}$ solution, and $10 \mathrm{ml}$ of ethanol. The precipitants obtained by hydrothermal synthesis were dispersed through ultrasonic treatment at room temperature for $30 \mathrm{~min}$, and the solution was synthesized in an enclosed SUS reactor at $200-250^{\circ} \mathrm{C}$ for $24 \mathrm{~h}$. After cooling down the heated reactants to room temperature, the solid sediments were collected. In order to clean the remaining precursors of the solids obtained, repeat the process of separating water from solid elements by centrifuging the specimens after filling them with water. Finally, the $\mathrm{ZrO}_{2}$ nanorods were obtained by drying the solids at $80^{\circ} \mathrm{C}$ for $12 \mathrm{~h}$.

\subsection{Membrane Fabrication}

A $\mathrm{ZrO}_{2} /$ polysulfone composite porous membrane was fabricated using the film-casting technique. After dissolving polysuflone in NMP at $50^{\circ} \mathrm{C}$ (PSU:NMP=82:18), $\mathrm{ZrO}_{2}$ nanoparticles were added to the solution to be about 80 wt.\%. The $\mathrm{ZrO}_{2}$ used for fabrication were prepared by mixing nanorods, obtained from hydrothermal synthesis, with the commercial spherical powder at various proportions (spherical powder:nanorod=90:10, 95:5). The mixture was continu- ously agitated at a speed of $2,000 \mathrm{rpm}$ at $50^{\circ} \mathrm{C}$ for $3 \mathrm{~h}$ until uniform viscosity was obtained. The suspension was cast into the form of membrane on a glass plate using a doctor blade having a gap size of $300^{\circ} \mathrm{C}$. Using a polyphenylene sulfide mesh (PPS80PW, PVF) as a support layer with the suspension, the second cast was performed at a thickness of $600^{\circ} \mathrm{C}$. The membrane was retrieved by dipping the casted glass sheet in deionized water at room temperature, and rinsed $2 \sim 3$ times in deionized water before being used in the experiment.

\subsection{Surface Characterization and Performance Evaluation}

$\mathrm{ZrO}_{2}$ nanorods obtained from hydrothermal synthesis were analyzed using X-ray diffraction (XRD) (CuKa, Rigaku Model D/MAX 2500) and a scanning electron microscope (SEM, HITACHI S-4700, acceleration voltage of $20 \mathrm{kV}$ ). Bubble point pressure was measured to assess the durability when the membrane was subjected to pressure during the operation of water electrolysis system. For this purpose, a specially fabricated device was fixed onto the membrane to measure the pressure when the first bubble was formed by increasing the gas pressure at the bottom and filling the upper part with solvent such as water or alcohol. The ionic resistance per unit area of the membrane was measured by subtracting the cell resistance in the absence of a membrane from the cell resistance with the membrane in $30 \%$ $\mathrm{KOH}$ at $30^{\circ} \mathrm{C}$ and then multiplying by the area.

\section{Results and Discussion}

\subsection{The Shape of Zirconia Nanorod Depending on} the Synthesis Conditions

3.1.1. Effect of Precursor Concentration

$\mathrm{ZrO}_{2}$ nanorods were synthesized while varying the concentration of zirconium precursor and $\mathrm{NaOH}$.

Figure 1 shows the XRD patterns of commercial $\mathrm{ZrO}_{2}$

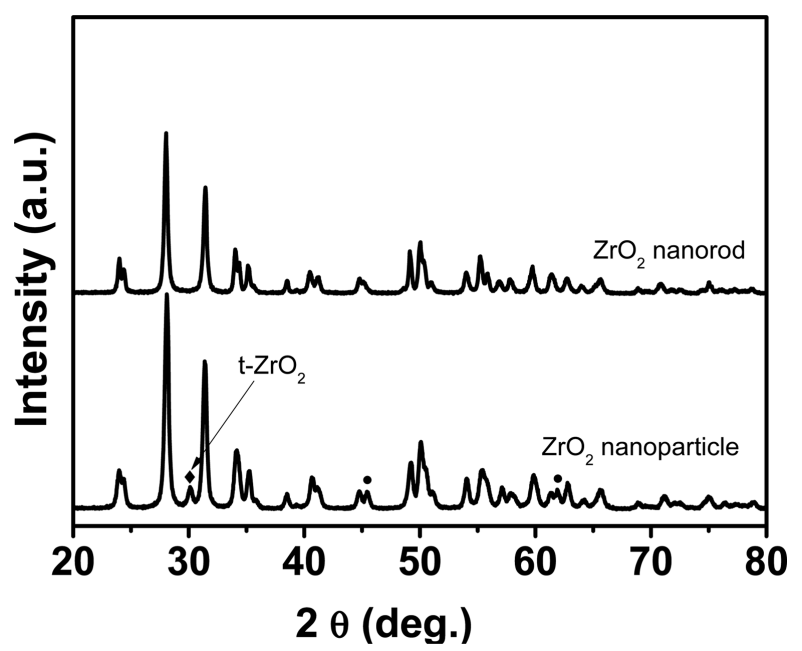

Fig. 1. XRD patterns of zirconium oxide nanoparticles and nanorods. 

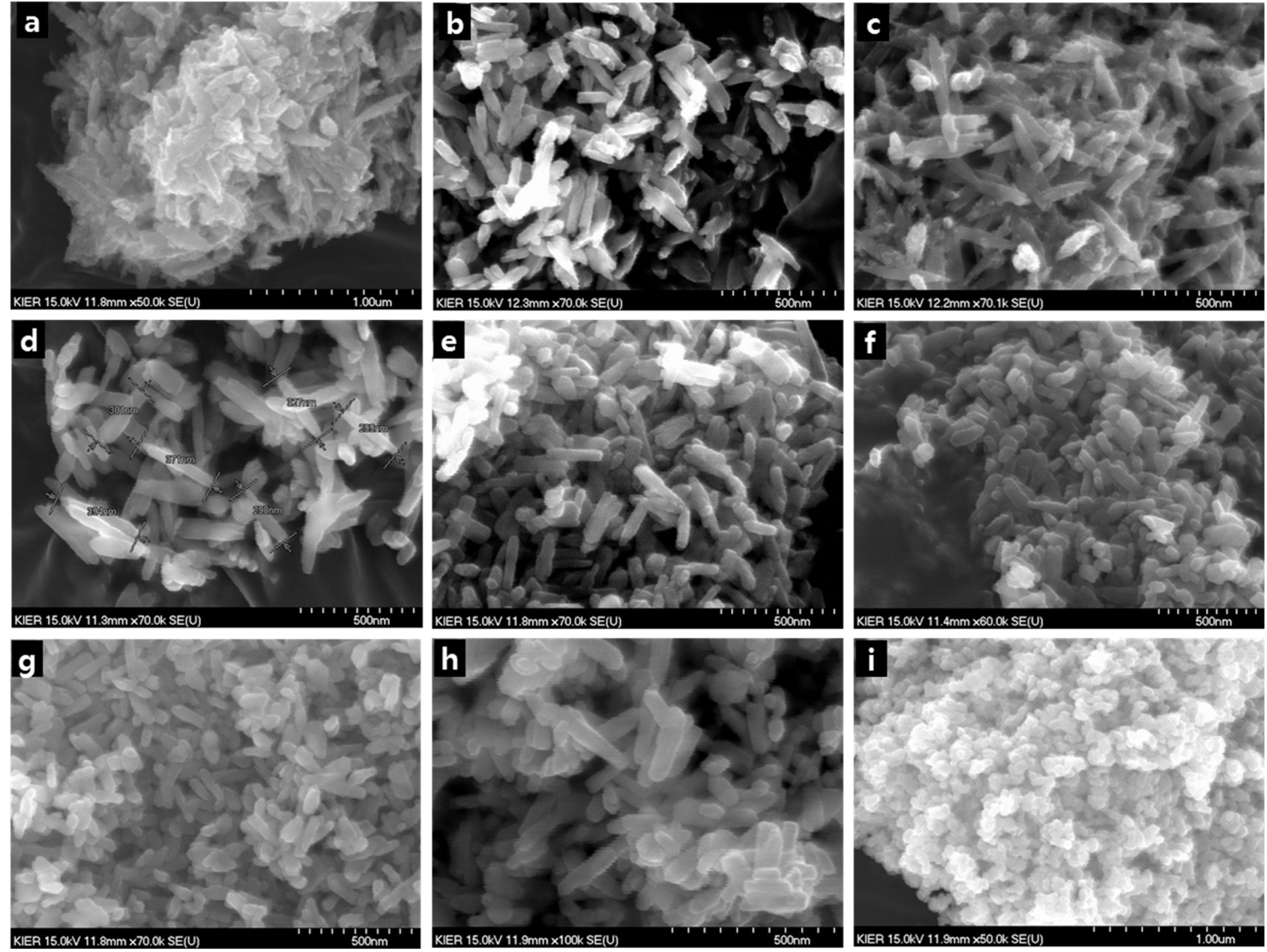

Fig. 2. SEM images of $\mathrm{ZrO}_{2}$ nanorods depending on the concentration of $\mathrm{Zr}\left(\mathrm{NO}_{3}\right)_{2}$ precursor solution (a) $0.01 \mathrm{~mol}$, (b) 0.03 mol, (c) $0.05 \mathrm{~mol}$, (d) $0.07 \mathrm{~mol}$, (e) $0.1 \mathrm{~mol}$, (f) $0.2 \mathrm{~mol}$, (g) $0.3 \mathrm{~mol}$, (h) $0.5 \mathrm{~mol}$, (i) $1.0 \mathrm{~mol}$ ( $\mathrm{NaOH}$ solution concentration: $10 \mathrm{~mol}$, temperature: $200^{\circ} \mathrm{C}$, synthesis time: $24 \mathrm{~h}$ ).

nanoparticles (Fig. 1(a)) and $\mathrm{ZrO}_{2}$ nanorods obtained by hydrothermal synthesis at $200^{\circ} \mathrm{C}$ for $24 \mathrm{~h}$ (Fig. 1(b)). ${ }^{22)}$ Based on JCPDS-65-1022 (pure $\mathrm{ZrO}_{2}$ ), JCPDS-80-0965, JCPDS42-1164 (tetrahedral $\mathrm{ZrO}_{2}$ ), and JCPDS-37-1484 (monoclinic $\mathrm{ZrO}_{2}$ ), commercial $\mathrm{ZrO}_{2}$ nanoparticles (Fig. 1(a)) exist in pure monoclinic $\mathrm{ZrO}_{2}$ phase and partially in tetragonal $\mathrm{ZrO}_{2}$ phase. In the result of $\mathrm{ZrO}_{2}$ nanorods shown in Fig. 1(b), only pure monoclinic $\mathrm{ZrO}_{2}$ phase is observed, which is different from the commercial $\mathrm{ZrO}_{2}$ nanoparticles. The XRD analysis indicates that the commercial nanoparticles synthesized at higher temperatures contain both $\mathrm{m}-\mathrm{ZrO}_{2}$ and $\mathrm{t}$ $\mathrm{ZrO}_{2}$, while the lab-made nanorods consist of pure $\mathrm{m}-\mathrm{ZrO}_{2}$ -

Synthesis conditions such as concentration of the precursor solution, synthesis temperature, synthesis time, and aging time were varied, and their effects on the shape of nanorods were examined. Fig. 2 shows SEM images of the nanorods under different concentrations of $\mathrm{Zr}$ precursor solutions while keeping the concentration of $\mathrm{NaOH}$ solution at $10 \mathrm{~mol}$. As can be seen from the images, the powder is rod-shaped instead of spherical when the concentration of $\mathrm{Zr}$ precursor solution is in the range of $0.03 \mathrm{~mol}-0.5 \mathrm{~mol}$. To enhance the understanding of the relationship between the concentration of the $\mathrm{Zr}$ precursor solution and the nanorod

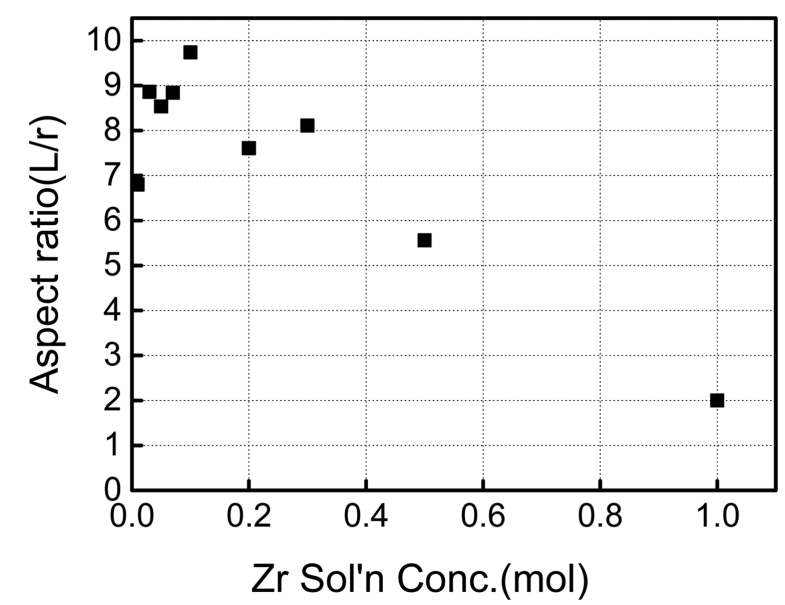

Fig. 3. Aspect ratio of $\mathrm{ZrO}_{2}$ nanorod depending on $\mathrm{Zr}\left(\mathrm{NO}_{3}\right)_{2}$ solution concentration ( $\mathrm{NaOH}$ solution concentration: $10 \mathrm{~mol}$, temperature: $200^{\circ} \mathrm{C}$, synthesis time: $24 \mathrm{~h}$ ). 

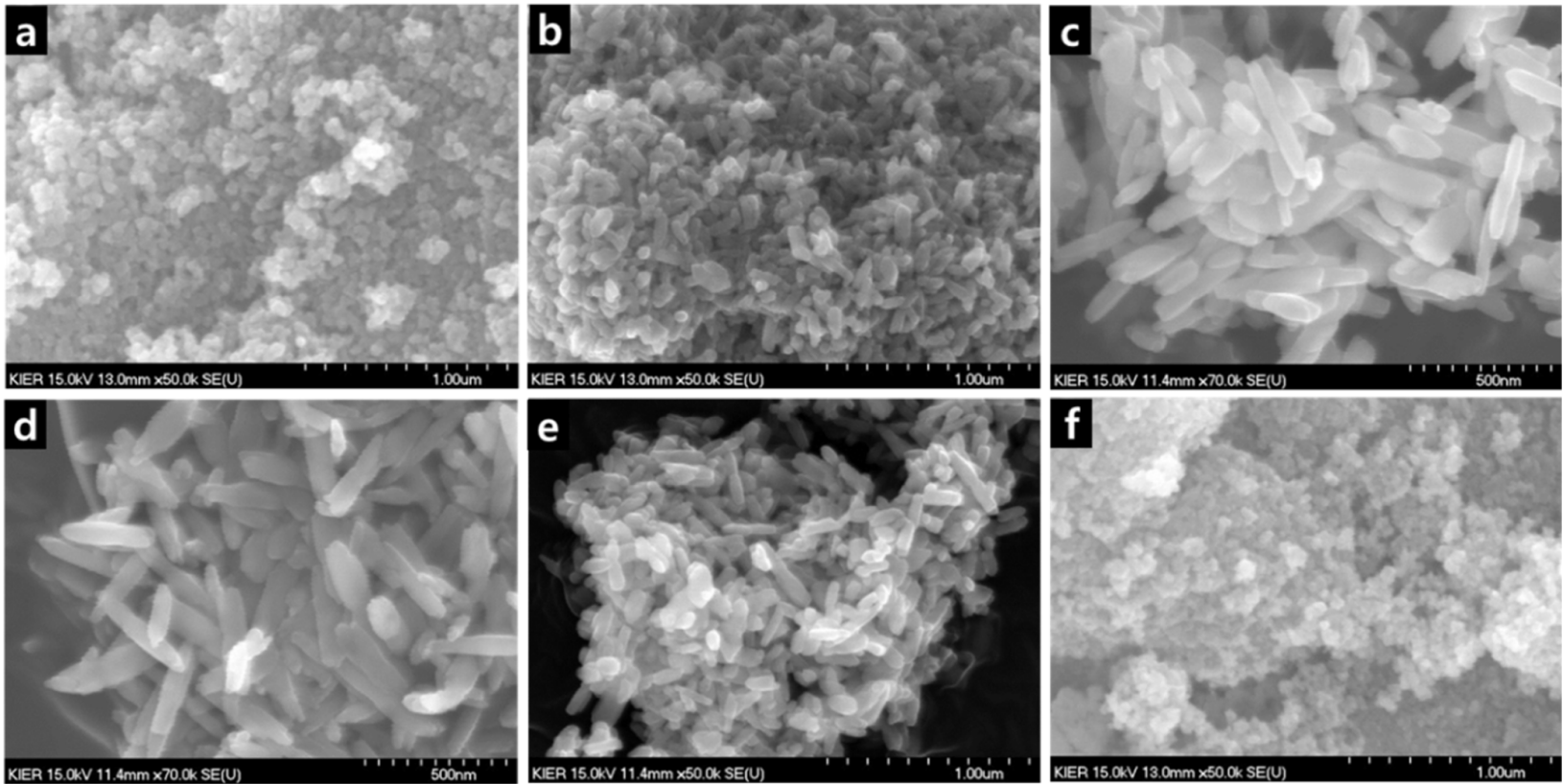

Fig. 4. SEM images of $\mathrm{ZrO}_{2}$ nanorods depending on the concentration of $\mathrm{NaOH}$ solution (a) $5 \mathrm{~mol}$, (b) $7 \mathrm{~mol}$, (c) $10 \mathrm{~mol}$, (d) 12 mol, (e) $15 \mathrm{~mol}$ and (d) $20 \mathrm{~mol}\left(\mathrm{ZrO}_{2}\right.$ solution concentration: $0.5 \mathrm{~mol}$, temperature: $200^{\circ} \mathrm{C}$, synthesis time: $\left.24 \mathrm{~h}\right)$.

shape, the average aspect ratio of $\mathrm{Zr}$ nanorods was measured under different conditions and presented as a function of $\mathrm{Zr}$ concentration (Fig. 3). The synthesized $\mathrm{ZrO}_{2}$ nanorods had larger aspect ratios for less concentrated $\mathrm{Zr}$ solutions, and showed the greatest aspect ratio at a concentration of $0.1 \mathrm{~mol}$. This can be traced to the hydrolysis rate of zirconium cations and the structure directing role of $\mathrm{NaOH}$, which serves as a capping agent, in the synthesis of $\mathrm{ZrO}_{2}$ nanorods. That is, the hydrolysis rate of zirconium cations accelerates with increasing concentration of the $\mathrm{Zr}$ precursor, leading to the synthesis of rods with smaller aspect ratios as presented in Fig. 3. On the other hand, if $\mathrm{Zr}$ solution is less concentrated, the hydrolysis rate of zirconium cations slows down, and the resulting rods tend to have larger aspect ratios. Meanwhile, the aspect ratio decreases when the concentration of the $\mathrm{Zr}$ precursor solution falls below $0.1 \mathrm{~mol}$, which is considered to be due to insufficient concentration of $\mathrm{Zr}$ precursor for nanorod synthesis. Regardless, the nanorods produced under this condition had relatively high aspect ratios in the range of 7-9.

While maintaining the concentration of the zirconium precursor solution at $0.5 \mathrm{~mol}$, the shapes of $\mathrm{ZrO}_{2}$ nanorods depending on the $\mathrm{NaOH}$ concentration were observed by SEM (Fig. 4), and the aspect ratio of the $\mathrm{Zr}$ nanorods was measured for each case (Fig. 5). The aspect ratio is 2.1 at an $\mathrm{NaOH}$ solution concentration of $7 \mathrm{~mol}, 5.56$ at a concentration of $10 \mathrm{~mol}$, and 6.8 at a concentration of $12 \mathrm{~mol}$, and peaked at a concentration of 10-12 mol. During hydrothermal synthesis, $\mathrm{Zr}$ precursors existing as $\mathrm{Zr}-\mathrm{NO}_{3}-\mathrm{Zr}$ experienced hydrolysis in the presence of $\mathrm{NaOH}$, resulting in $\mathrm{Zr}$ $\mathrm{NO}_{3}-\mathrm{Na}$ and $\mathrm{Zr}-\mathrm{OH}$ bonds. At this point, increasing the $\mathrm{NaOH}$ concentration raises the $\mathrm{pH}$ of the solution and pro-

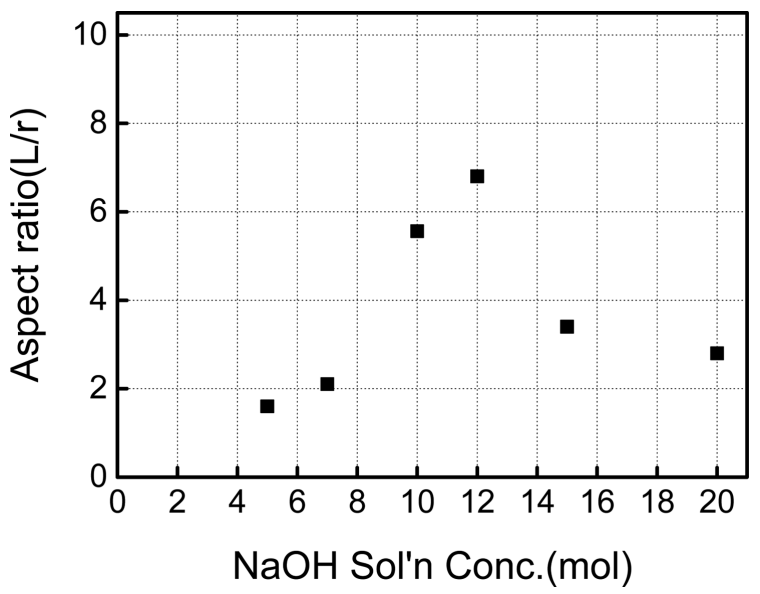

Fig. 5. Aspect ratio of $\mathrm{ZrO}_{2}$ nanorods depending on $\mathrm{NaOH}$ solution concentration $\left(\mathrm{ZrO}_{2}\right.$ solution concentration: $0.5 \mathrm{~mol}$, temperature: $200^{\circ} \mathrm{C}$, synthesis time: $24 \mathrm{~h}$ ).

motes hydrolysis. Surface energy is lowered with strong adsorption of these bonds on the $\mathrm{m}-\mathrm{ZrO}_{2}$ surface, and $\mathrm{ZrO}_{2}$ crystals grow in the lengthwise direction. That is, the higher the concentration of $\mathrm{NaOH}$ is, the greater the aspect ratio of the nanorods will be. ${ }^{23)}$ However, if the concentration of $\mathrm{NaOH}$ exceeds a certain level, $\mathrm{NaOH}$ acts as a capping agent in the mixture, thus causing a decrease in the aspect ratio.

To obtain $\mathrm{ZrO}_{2}$ nanorods with optimal shapes, it is important to optimize not only the production rate of $\mathrm{Zr}$ cations and the hydrolysis rate due to $\mathrm{NaOH}$ addition, but also the aspect ratio of the resulting nanorods. In this study, the optimal synthesis conditions that maximized the aspect 
ratio were a $\mathrm{Zr}$ precursor concentration of $0.2-0.5 \mathrm{~mol}$ and a $\mathrm{NaOH}$ solution concentration of 10-12 mol. Under these conditions, the BET surface area of the obtained nanorod powder was $17.8 \mathrm{~m}^{2} / \mathrm{g}$.

3.1.2. Effects of Reaction Time, Aging Time, and Reaction Temperature

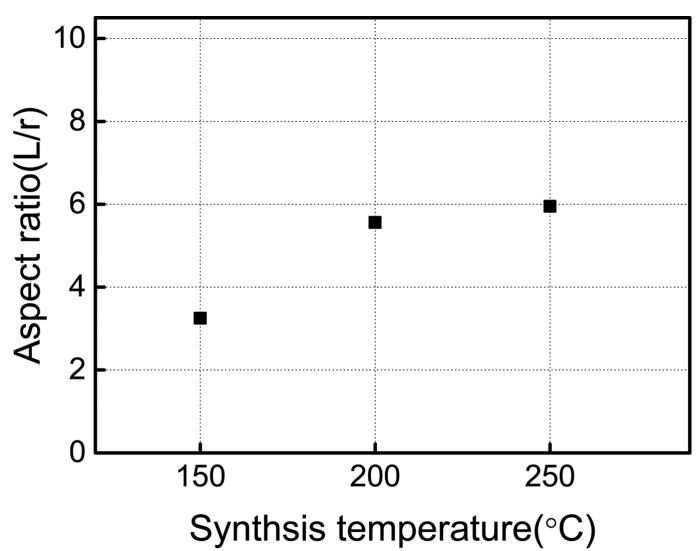

(a)

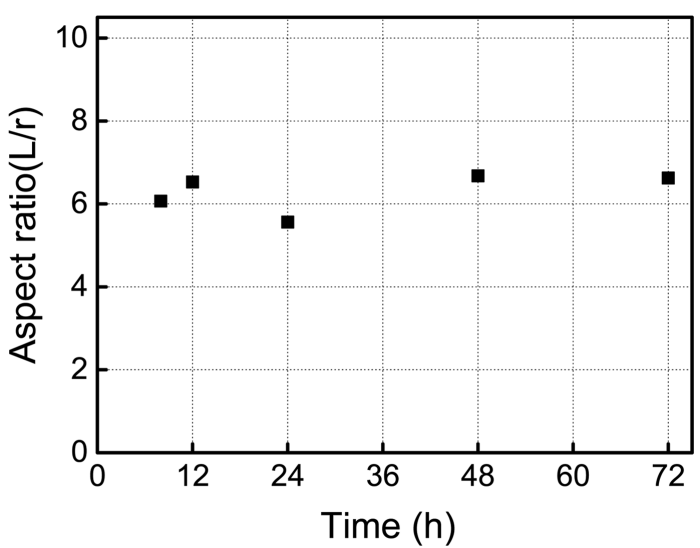

(b)

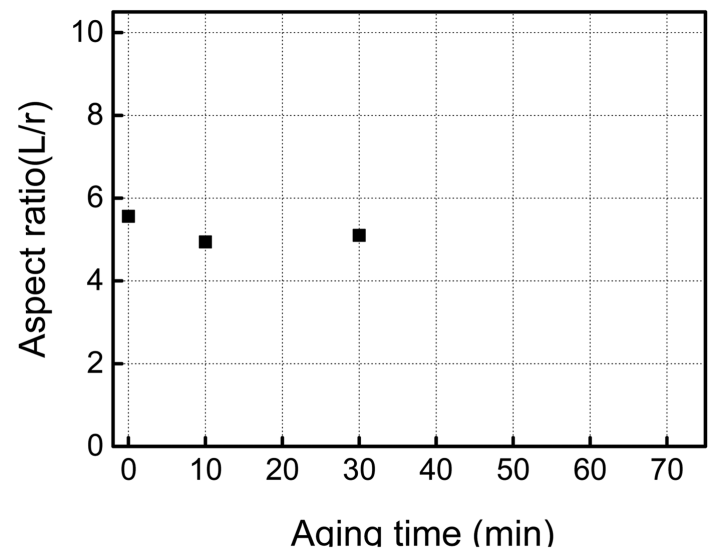

(c)

Fig. 6. Effect of (a) synthesis temperature, (b) synthesis time and (c)aging time on the aspect ratio of $\mathrm{ZrO}_{2}$ nanorods (concentration of $\mathrm{Zr}\left(\mathrm{NO}_{3}\right)_{2}$ solution $0.5 \mathrm{~mol}$, $\mathrm{NaOH}$ concentration $10 \mathrm{~mol})$.
To optimize the shape of the $\mathrm{Zr}$ nanorods, the aspect ratio of the nanorods was measured after varying conditions such as hydrothermal synthesis time, subsequent aging time at room temperature, and reaction temperature. In this case, the concentration of the $\mathrm{Zr}$ precursor solution was kept at $0.5 \mathrm{~mol}$, and that of the $\mathrm{NaOH}$ solution at $10 \mathrm{~mol}$. Fig. 6(a) gives the aspect ratio of $\mathrm{ZrO}_{2}$ nanorods obtained from varying the synthesis temperature in the range of $150-250^{\circ} \mathrm{C}$. The aspect ratio increases with synthesis temperature, and remains similar after $200^{\circ} \mathrm{C}$. That is, the aspect ratio of the nanorods was 3.2 when they are synthesized at $150^{\circ} \mathrm{C}, 5.5$ when synthesized at $200^{\circ} \mathrm{C}$, and increased up to 6.0 when synthesized at $250^{\circ} \mathrm{C}$. Fig. 6 (b) shows the aspect ratio in relation to synthesis time, varied from 8 to $72 \mathrm{~h}$. The aspect ratio was about 6 regardless of the synthesis time, indicating that the shape of the nanorods is unaffected by synthesis time, but more directly influenced by other factors such as synthesis temperature and precursor concentration. Fig. 6(c) shows the lengthwise growth of nanorods with additional aging treatment, and aging time was found to have little influence on the growth of the rods. Consequently, aging time and reaction time did not affect the shape of the nanorods, and synthesis temperature was insignificant in the range of $200-250^{\circ} \mathrm{C}$. Based on these results, subsequent synthesis processes were carried out at a reaction temperature of $200^{\circ} \mathrm{C}$ for $24 \mathrm{~h}$ with no aging treatment. The nanorods used for the membrane casting in this study had an aspect ratio of approximately 5.5. Membrane performance may be improved to further extent by replacing nanorods with those having a larger aspect ratio. The nanorods in this study had an average width of $45 \mathrm{~nm}$, length of $257 \mathrm{~nm}$, and aspect ratio of 5.5.

\subsection{Evaluation of Membrane Performance in Zirco- nia Nanorods}

Membranes were made by mixing $\mathrm{ZrO}_{2}$ nanorods with $\mathrm{ZrO}_{2}$ spheres at fixed proportions, and basic performances were evaluated for application in an alkaline water electrolysis system. Commercial $\mathrm{ZrO}_{2}$ spheres and $\mathrm{ZrO}_{2}$ nanorods were mixed in two different ratios: 90:10 and 95:5. Fig. 7 presents SEM images of (a) a commercial Zirfon membrane and (b) a lab-made membrane containing $10 \%$ nanorods. As shown in the SEM images, the particles in (b) are less uniformly coated and have more amount of empty spaces compared to the commercial Zirfon membrane. Such spaces may weaken the mechanical strength of the membrane and provide less control over gas permeation, and thus additional improvement of the manufacturing methods is considered necessary.

In order to evaluate the physical property of the membrane, bubble point and ionic resistance were measured, and the results were compared to those of a commercial Zirfon membrane. As shown in Table 1, commercial $\mathrm{ZrO}_{2}$ nanopowder and $\mathrm{ZrO}_{2}$ nanorods mixed in a ratio of 9:1 showed a bubble point of $0.3 \mathrm{bar}$, which was far lower than that of the Zirfon membrane ( $3 \pm 1$ bar). When $\mathrm{ZrO}_{2}$ nanorods were 

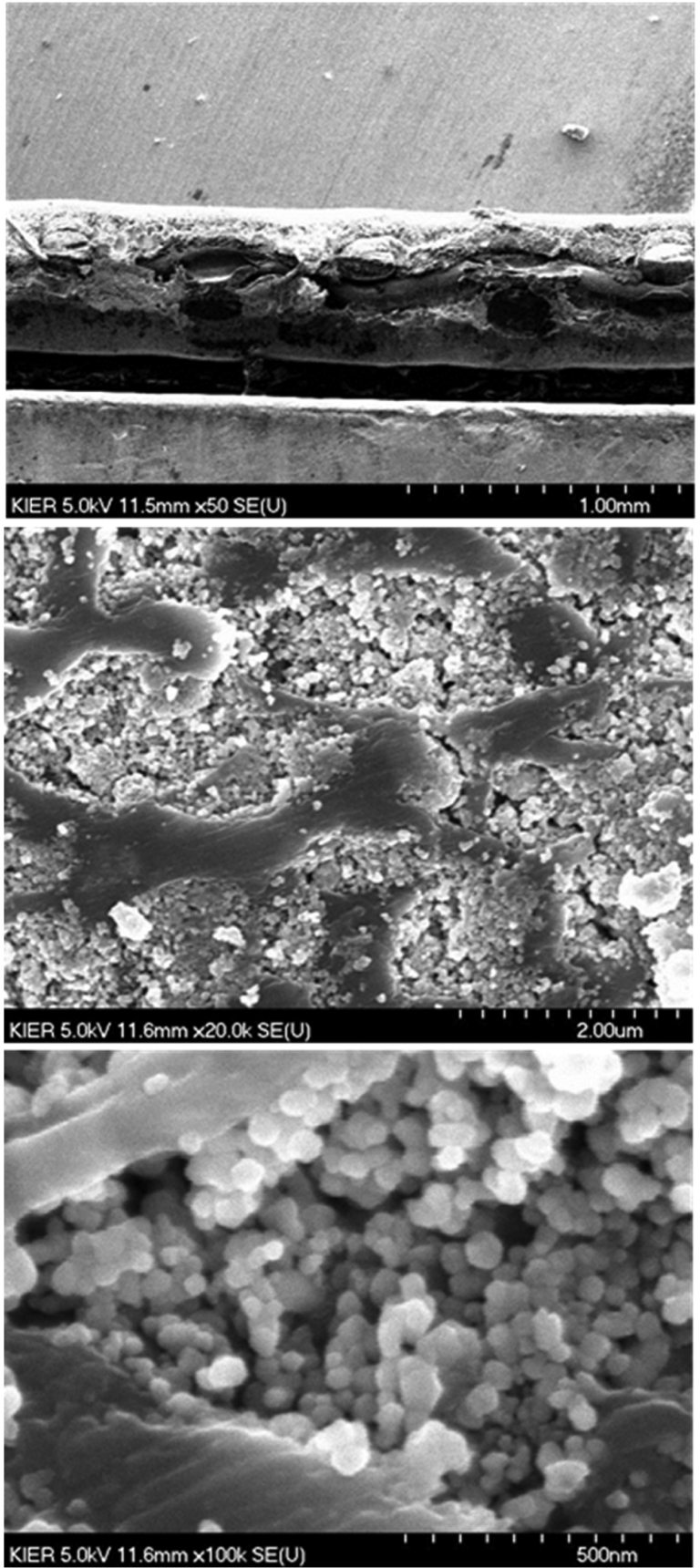

(a)
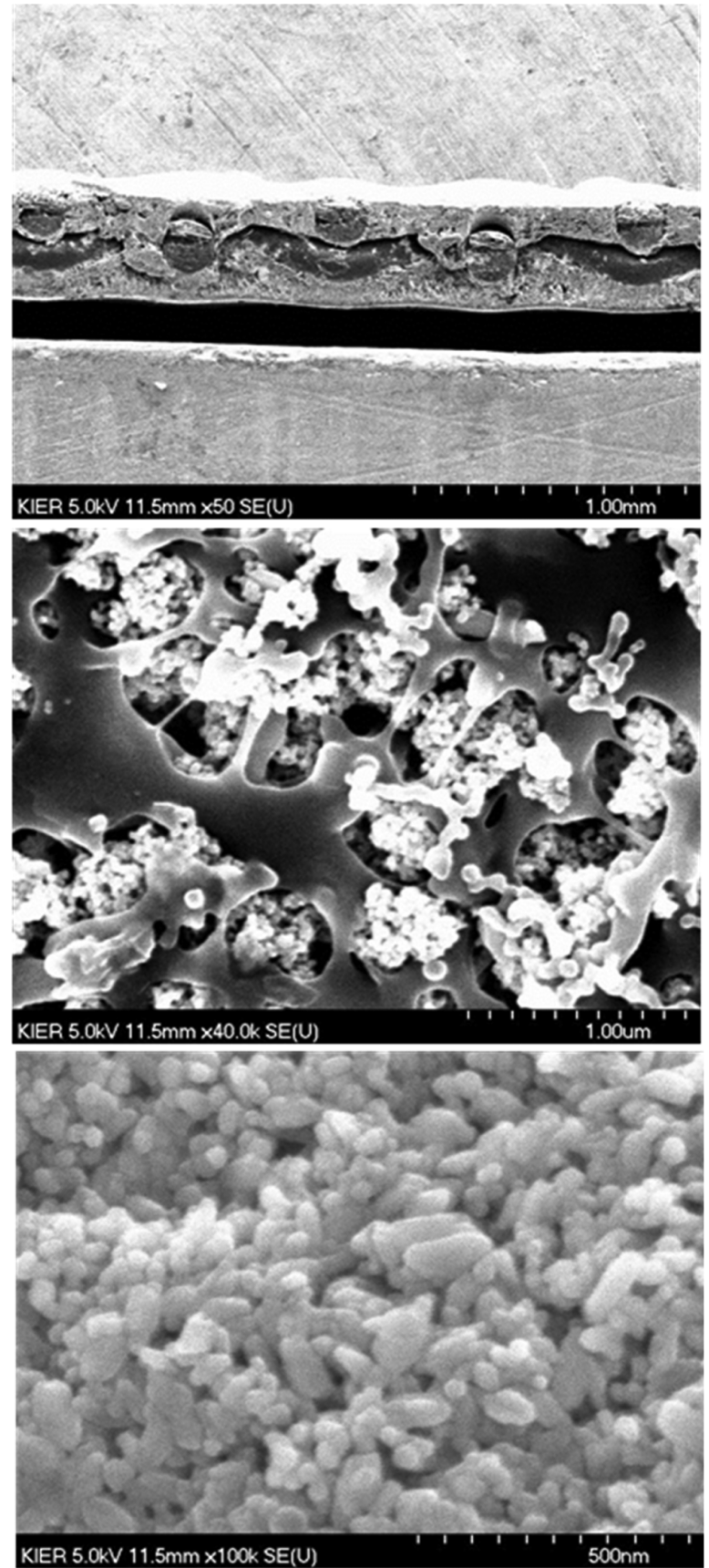

(b)

Fig. 7. SEM images of $\mathrm{ZrO}_{2}$ membrane, (a) commercial Zirfon membrane (left) and (b) lab-made $\mathrm{ZrO}_{2}$ membrane ( $\mathrm{ZrO}{ }_{2}$ nanorod $10 \%+\mathrm{ZrO}_{2}$ sphere) (right)

mixed at $5 \mathrm{wt} . \%$, the bubble point increased to around 0.8 bar, which is improved compared to the value obtained by adding 10 wt.\% nanorods. However, this value was still much lower than that of the existing membrane. The membrane produced with $10 \%$ nanorods had an ionic resistance of $0.086 \Omega \cdot \mathrm{cm}^{2}$, while the membrane with $5 \%$ nanorods had a higher ionic resistance of $0.18 \Omega \cdot \mathrm{cm}^{2}$. Both were higher than that of commercial Zirfon, which recorded a value smaller than $0.3 \Omega \cdot \mathrm{cm}^{2}$. As can be deduced from the SEM images, membranes prepared by mixing nanorods have a less uniform surface and are more prone to cracks, which contribute to a lower bubble point. In follow-up studies, membrane performance can be improved by optimizing the mixing ratio and the shapes of nanorods (aspect ratio, length, thickness, etc.) according to the required membrane performance. Another approach to improve membrane performance is to increase the wettability of the nanorod surface. Meanwhile, the ionic resistance of the membrane 
Table 1. Basic Characteristics of $\mathrm{ZrO}_{2}$-Nanorod Membrane

\begin{tabular}{lccc}
\hline \multicolumn{1}{c}{ Membrane (materials) } & Thickness $(\mu \mathrm{m})$ & Bubble point (bar) & $\begin{array}{c}\text { Ion Resistance }\left(\Omega \cdot \mathrm{cm}^{2}\right) \\
\left(30^{\circ} \mathrm{C}, 30 \% \mathrm{KOH} \text { sol'n) }\right.\end{array}$ \\
\hline Lab-made I (Nanorod 10\%/nanosphere 90\%) & $480 \pm 10$ & 0.3 & 0.086 \\
Lab-made II (Nanorod 5\%/nanosphere 95\%) & $490 \pm 10$ & 0.8 & 0.18 \\
Zirfon membrane & $500 \pm 50$ & $3 \pm 1$ & $<0.3$ \\
\hline
\end{tabular}

significantly dropped due to the mixing of nanorods, because the nanorods have higher ionic conductivity than spherical powder. In conclusion, by applying the $\mathrm{ZrO}_{2}$ nanorod material to the alkaline water electrolytic separator, it is possible to produce a membrane having excellent mechanical strength and excellent ion conductivity.

\section{Conclusions}

Based on the $\mathrm{ZrO}_{2}$ materials widely used in various energy materials and devices, the $\mathrm{ZrO}_{2}$ nanorods were synthesized in a simple process at low temperature. The applicability of these nanorods as a membrane material of the alkaline water electrolysis system was evaluated. The shape and the aspect ratio of the $\mathrm{ZrO}_{2}$ nanorods were affected by the composition and the concentration of the precursors and the synthesis temperature. The synthesis conditions that allowed the formation of nanorods with a maximum aspect ratio were a $\mathrm{Zr}$ precursor solution concentration of $0.2-0.5$ mol and a $\mathrm{NaOH}$ aqueous solution concentration of $10-12$ mol.

The synthesized nanorods were mixed with a commercial spherical nanopowder at fixed proportions to fabricate the membrane for an alkaline water electrolysis system. Basic properties such as bubble point and ionic resistance were measured. The bubble point tends to decrease when $\mathrm{ZrO}_{2}$ nanorods are mixed with the commercial nanoparticles, and this is presumed to be due to the structural non-uniformity of the lab-made membrane. The desired bubble point may be attained by optimizing the surface wettability of nanorods, aspect ratio, length, and thickness in our subsequent research. The ionic resistance of the membrane dropped due to the mixing of nanorods because which have higher ionic conductivity than conventional spherical $\mathrm{ZrO}_{2}$. Based on these results, the performance of membrane for alkaline water electrolysis system may be further improved through surface modification and shape optimization of the $\mathrm{ZrO}_{2}$ nanorods.

\section{Acknowledgments}

This work was supported by Technology Development Program to Solve Climate Changes through the National Research Foundation of Korea (NRF) funded by the Ministry of Science, ICT (NRF-2016M1A2A2940138 and NRF2015M1A2A2074657).

\section{REFERENCES}

1. M. Florea, F. Matei-rutkovska, G. Postole, A. Urda, F. Neatu, V. I. Pârvulescu, and P. Gelin, "Doped Ceria Prepared by Precipitation Route for Steam Reforming of Methane, "Catal. Today., 306 166-71 (2018).

2. S. Okada, R. Manabe, R. Inagaki, S. Ogo, and Y. Sekine, "Methane Dissociative Adsorption in Catalytic Steam Reforming of Methane over $\mathrm{Pd} / \mathrm{CeO}_{2}$ in an Electric Field," Catal. Today., 307 272-76 (2018).

3. T. G. Ko, K. S. Han, T. K. Rim, S. G. Oh, and S. W. Han, "Photoluminescence and Fabrication of Zirconia Nanofibers from Electrospinning an Alkoxide Sol Templated on a Polyvinyl Butyral," J. Korean Ceram. Soc., 47 [4] 34352 (2010).

4. H. J. Noh, J. K. Lee, D. S. Seo, and K. H. Hwang, "Preparation of Zirconia Nanocrystalline Powder by the Hydrothemal Treatment at Low Temperature," J. Korean Ceram. Soc., 39 [3] 308-14 (2002).

5. N. M. Hwang, I. D. Jeon, L. Gueroudji and D. Y. Kim, "Temperature Dependence of the Deposition Behavior of Yttria-stabilized Zirconia CVD Films: Approach by Charged Cluster Model," J. Korean Ceram. Soc., 38 [3] 218-24 (2001)

6. M. Rawat, and V. K. Bulasara, "Synthesis and Characterization of Low-Cost Ceramic Membranes from Fly Ash and Kaolin for Humic Acid Separation," Korean J. Chem. Eng., 35 [3] 725-33 (2018).

7. Y. S. Kang, J. O. Won, and I. N. Yoon, "Electrolytes Containing Nano-Rod Ion Channels for Dye-sensitized SolarCells and Manufacturing Method of the Same"; KOR Patent 20130046101A, 2011.

8. K. G. Lee, D. C. Lim, J. H. Lim, A. Y. Jang, D. Chang, Hwang, and E. Hong, "Carbon Fiber Comprising ZnO Nano-rod and Fabrication Method of the Same"; KOR Patent 20140145664A, 2015.

9. Y. Wang, L. Yao, S. Wang, D. Mao, and C. Hu, "Low-Temperature Catalytic $\mathrm{CO}_{2}$ Dry Reforming of Methane on Nibased Catalysts?: A Review," Fuel Process. Technol., 169 199-206 (2018).

10. D. Yap, T. Jean-michel, and B. D. Catherine, "Catalyst Assisted by Non-thermal Plasma in Dry Reforming of Methane at Low Temperature," Catal. Today., 299263 71 (2018).

11. A. Sivanantham and S. Shanmugam, "Nickel Selenide Supported on Nickel Foam as an Efficient and Durable Non-Precious Electrocatalyst for the Alkaline Water Electrolysis," Appl. Catal. B Environ., 203 485-93 (2017).

12. K. G. Kanade, J. O. Baeg, S. K. Apte, T. L. Prakash, and 
B. B Kale, "Synthesis and Characterization of Nanocrystallined Zirconia by Hydrothermal Method," Mater. Res. Bull., 43 723-29 (2008).

13. R. A. Espinoza-gonzález, D. E. Diaz-droguett, J. I. Avila, C. A. Gonzalez-fuentes, and V. M. Fuenzalida, "Hydrothermal Growth of Zirconia Nanobars on Zirconium Oxide," Mater. Lett., 65 2121-23 (2011).

14. K. Zeng and Z. Dongke, "Recent Progress in Alkaline Water Electrolysis for Hydrogen Production and Applications," Prog. Energy Combust. Sci., 36 [3] 307-26 (2010).

15. S. Marini, P. Salvi, P. Nelli, E. Pesenti, M. Villa, M. Berrettoni, G. Zangari, and Y. Kiros, "Advanced Alkaline Water Electrolysis," Electrochimi. Acta., 82 384-91 (2012).

16. D. M. F. Santos, C. A. C. Sequeira, and J. L. Figueirdo, "Hydrogen Production by Alkaline Water Electrolysis," Quim. Nova., 36 [8] 1176-93 (2013).

17. E. Montoneri, G. Modica, and E. Tempesti, "Reinforced Asbestos Separators for Water Electrolysis," Int. J. Hydrogen Energy, 11 [4] 233-40 (1986).

18. M. Paidar, V. Fateev, and K. Bouzek, "Membrane Electrolysis - History, Current Status and Perspective," Elec- trochimi. Acta., 209 737-56 (2016)

19. P. Aerts, S. Kuypers, I. Genne, R. Leysen, J. Mewis, and I. F. J. Vankelecom, "Polysulfone - $\mathrm{ZrO}_{2}$ Surface Interactions. The Influence on Formation, Morphology and Properties of Zirfon-membranes," J. Phys. Chem. B, 110 7425-30 (2006).

20. W. Adriansens and R. Leysen, "A New Separator for Ni-H, Fuel Cells Batteries," Int. J. Hydrogen Energy, 21 [8] 679_ 84 (1996).

21. P. H. Vermeiren, J. P. Moreels, and R. Leysen, "Porosity in Vompositezirfon ${ }^{\circledR}$ Membranes," J. Porous Mater., 3 3340 (1996).

22. T. Ulrike, " $\mathrm{TiO}_{2}$-Doped Zirconia: Crystal Structure, Monoclinic-Tetragonal Phase Transition, and the New Tetragonal Compound $\mathrm{Zr}_{3} \mathrm{TiO}_{8}$, J. Am. Ceram. Soc., 89 [10] 3201-210 (2006).

23. C. Aling, Z. Yan, M. Sue, L. Yong, and S. Wenjie, "Assembly of Monoclinic $\mathrm{ZrO}_{2}$ nanorods: Formation Mechanism and Crystal Phase Control," CrystEngComm, 18 580-87 (2016). 